\title{
INVESTIGATING FILLER CHARACTERISTICS IN UPGRADING COLD BITUMINOUS EMULSION MIXTURES
}

Dr. Shakir Al-Busaltan, Lecturer, Department of Civil Engineering, College of Engineering, University of Kerbala, Kerbala, Iraq. Email: s.f.al-busaltan@uokerbala.edu.iq

doi: 10.2478/ijpeat-2013-0012

\begin{abstract}
Cold Bituminous Emulsion Mixtures (CBEMs) could offer significant advantages in contrast to traditional Hot Mix Asphalt (HMA). These advantages are redaction of energy consumption, reduction of emission of pollutants, and reduction of total costs. To date, researchers have attempted, intensively, to upgrade CBEMs' engineering characteristics to gain their whole advantages. Adding active filler materials such as Ordinary Portland Cement (OPC) develop these characteristics. In this paper, selected waste or by-product materials are investigated as alternatives to OPC. Although OPC alone or with activator has proven successful in improving curing time and mechanical properties, the successful use of waste or by-product alternatives could represent a unique environmental and economic achievement. Thus, for the first time, waste or by-product materials (PFA, PSA, GGBFS, APC, and BFA) were investigated individually and not as Supplementary Cementitious Material (SCM) for improving the curing and strength of CBEM. However, some of these filler showed significant improvement in CBEMs characteristics.
\end{abstract}

\section{Introduction}

Previous studies have proven the ability of Ordinary Portland Cement (OPC) in upgrading Cold Bituminous Emulsion Mixtures (Terrell and Wang, 1971, Schmidt et al., 1973, Head, 1974, Sainton and Bourdrel, 1993, Uemura and Nakamori, 1993, Li et al., 1998, Brown and Needham, 2000, Oruc et al., 2007, Niazi and Jalili, 2009, AlBusaltan et al., 2012b). These previous studies reported that the majority of water trapped between the emulsion film and the aggregates (which is the main cause of the inferiority in CBEMs characteristics) absorb due to hydration process. They also suggested that OPC develops a composite binder with bitumen; in contrast to base bitumen the developed binder has a lower penetration and a higher viscosity.

On other hand, waste or by-product materials were used widely as Supplementary Cement Materials (SCMs), in other words, as a partial replacement to Ordinary Portland Cement (OPC) in concrete construction materials (Concrete Society, 1991, Song and Saraswathy, 2006, Oner and Akyuz, 2007, Environmental Egency, 2008, Sarıdemir et al., 2009, Naik et al., 1994, Shirazi and Nrc, 1999, Geysen et al., 2004, Jerath and Hanson, 2007). However, some of these waste or by-product material have proven successful but up to a certain percentage of replacement.

The use of waste or by-product materials as replacements for OPC in CBEMs start with finding the answer to the question "What is unique in OPC to enhance CBEM, and is it available in waste and by-product materials with or without some sort of upgrading to their chemical and physical properties?". Of course cementitious 
characteristics is the main answer, but not the unique answer; because the improvement in curing time and strength depends on removing trapped water besides creating secondary binders, as mentioned above. Thus, other filler's characteristics have to investigate to answer the certain question.

Early study conducted by author investigated different waste or by-product filler to examine their validity for improving CBEM (Al-Busaltan, 2012). The selection of the filler was based on their cementitious and other characteristics or they used previously in cement development, plus of course their availability in commercial quantities in the UK and worldwide to a figure accommodate the demand in case they prove third validity to improve CBEM.

\section{Alternatives: Waste and By-Product Active Fillers}

As mentioned previously, replacing filler in CBEMs' approach was adopted in this study to upgrade CBEM. The developed cement-modified CBEM offered a reasonable reduction in environmental and economic impact in contrast to HMA. However, OPC production always seems to be associated with significant $\mathrm{CO} 2$ emissions (Karami, 2008, Taylor, 1997). For this reason, the author decided to study the potential of using waste and by-product materials as a replacement for OPC in CBEM. Waste and by-product materials, which initiate massive impact on landfills, are available in huge quantities and their uses provide social, economic, and environment benefits.

Filler is defined as aggregate, most of which passes through a $0.063 \mathrm{~mm}$ sieve, which can be added to construction materials to provide certain properties (BSI, 2002). Filler could be active or inert. Active filler is the filler that produces hydration in the presence of water, while inert filler does not. Active filler materials could be pozzolanic or cementitious. Pozzolanic is the materials that gain no strength when blended alone with water, such as SF, and low calcium PFA, while Cementitious (hydraulic) is the materials that gain strength when blended alone with water, such as GGBFS, and high calcium PFA.

Thus, the following waste or by-product filler were selected to examine their validity for improving CBEM. Their selection was dependent on their cementitious and other characteristics or they used previously in cement development, plus of course their availability in the UK and worldwide to a figure accommodate the demand in case they prove third validity to improve CBEM.

- Crushed aggregate mineral filler (CMF)

- Pulverized Fuel Ash (PFA)

- Paper Sludge Ash (PSA)

- Ground Granulated Blast Furnace Slag (GGBFS)

- Air Pollution Control (APC)

- Biomass Fly Ash (BFA) 


\section{Characterizing of the Active Filler}

Detailed investigation was achieved to characterize the chemical and physical properties of the selected waste active fillers. The main aim was to identify the similarity to OPC, plus explain their behaviour in CBEM.

\subsection{Experiments' Setup}

The following test methods were used to characterize the selected waste active filler:

\subsection{1 pH}

$\mathrm{pH}$ of the fillers was measured using a $\mathrm{pH}$ meter. A suspension of water with $3 \%$ filler content was prepared and tested at lab temperature, i.e. $20{ }^{\circ} \mathrm{C}$. Buffer solution was used for calibration before the measurement.

\subsubsection{Energy Dispersive X-ray Fluorescence (EDXRF):}

The elemental composition of materials (major oxides and trace elements) were analysed by Shimadzu EDX 720 , energy dispersive X-ray fluorescence spectrometer. This apparatus performs qualitative and quantitative elemental analysis and is ideal for non-destructive applications. The analysis is conducted by applying X-ray to the sample and then analysing the re-emitted characteristic fluorescent X-ray. Chemical composition by XRF analysis, with calculation of $\mathrm{Ca} / \mathrm{Si}$ oxides ratio, and sum of $\mathrm{Al}, \mathrm{Fe}$ and $\mathrm{Si}$ oxides were determined

\subsubsection{Surface Area}

The specific surface area of the fillers was determined following the model of Brunauer, Emmett and Teller (BET Method). Surface area is estimated from the quantity of nitrogen adsorbed in relationship with its pressure, at the boiling temperature of liquid nitrogen under normal atmospheric pressure. The test was conducted using NOVA 2000 model equipment.

\subsubsection{Particle Size Characteristics}

Beckmen Coulter Laser diffraction particle size analyser, was used for determining the grain size distribution of filler materials. Beckmen Coulter LS 13 320 utilizes reverse Fourier optics incorporated in a patented fibre optic spatial filter system and a binocular lens system.

\subsubsection{Morphology}

Morphological analysis was performed using Scanning Electron Microscopy (SEM). SEM applies a focused beam of high-energy electrons to create a variety of signals at the surface of solid test specimens. The signals that arise from electron-sample interactions disclose information about the sample, including external morphology (texture), chemical composition, and crystalline structure 
and orientation of materials making up the sample. SEM analysis was operated under the following conditions: resolution of 3-4 $\mathrm{nm}$; high vacuum and test voltage 12.5-20 kV. The SEM was also equipped with an energy-dispersive spectroscopy (EDS) containing Oxford Inca x-act detector with probe current 45 nA and counting time $100 \mathrm{sec}$.

\subsubsection{Density}

Density of the fillers was conducted according to BS EN 1097-7 (BSI, 2008) by means of a pyknometer. Density is calculated as the volume of irregularly formed samples (determined by replacing a certain amount of liquid of known density with the test portion) over known mass sample.

\subsection{Results}

Results of the mentioned test methods for the selected active fillers are shown as below:

- Table (1) illustrates the chemical compositions, surface area, density and filler particles' characteristics

- Figure (1) shows the percentages of the main oxides required for the hydration process

- Figure (2) presents the particle size distributions of selected fillers

- Figure (3) displays the morphology of the selected fillers

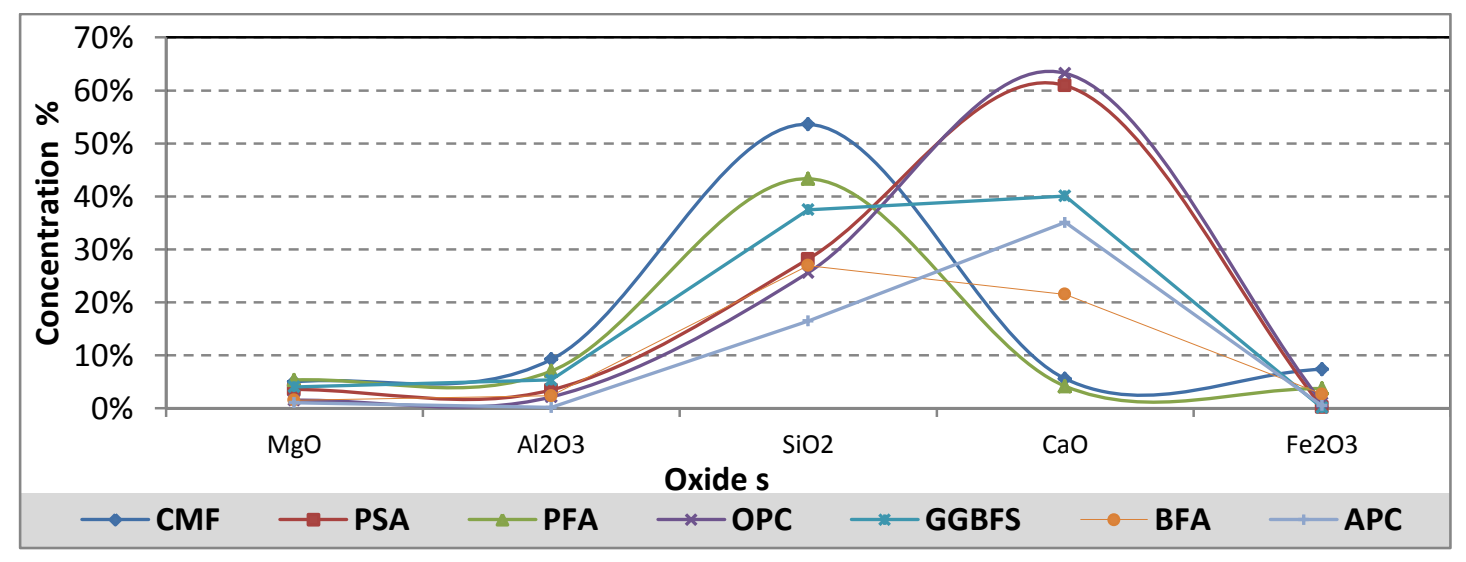

Figure (1). Main oxides percentages for the selected fillers 
The International Journal of Pavement Engineering and Asphalt Technology (PEAT) ISSN 1464-8164. Volume: 15, Issue: 2, December 2014, pp.54-71

Table (1). Chemical and physical characteristics of selected fillers

\begin{tabular}{|c|c|c|c|c|c|c|c|c|}
\hline \multicolumn{2}{|c|}{ Properties } & CMF & OPC & PFA & PSA & GGBFS & APC & BFA \\
\hline \multirow{17}{*}{$\begin{array}{l}\frac{0}{2} \\
\frac{0}{0} \\
3 \\
\frac{\hat{D}}{0} \\
\frac{0}{2} \\
\frac{0}{3} \\
\frac{0}{0} \\
\frac{0}{0} \\
\frac{0}{0}\end{array}$} & $\mathrm{Na}_{2} \mathrm{O}$ & $2.032 \%$ & $1.603 \%$ & $1.136 \%$ & $1.993 \%$ & $2.839 \%$ & $4.662 \%$ & $2.582 \%$ \\
\hline & $\mathrm{MgO}$ & $4.984 \%$ & $1.522 \%$ & $5.343 \%$ & $3.554 \%$ & $4.059 \%$ & $1.075 \%$ & $1.531 \%$ \\
\hline & $\mathrm{Al}_{2} \mathrm{O}_{3}$ & $9.221 \%$ & $2.147 \%$ & $7.039 \%$ & $3.471 \%$ & $5.333 \%$ & $0.135 \%$ & $2.350 \%$ \\
\hline & $\mathrm{SiO}_{2}$ & $53.597 \%$ & $25.611 \%$ & $43.326 \%$ & $28.178 \%$ & $37.488 \%$ & $16.465 \%$ & $26.953 \%$ \\
\hline & K2O & $3.123 \%$ & $0.774 \%$ & $1.470 \%$ & $0.354 \%$ & $0.620 \%$ & $1.755 \%$ & $3.552 \%$ \\
\hline & $\mathrm{CaO}$ & $5.580 \%$ & $63.246 \%$ & $4.174 \%$ & $60.927 \%$ & $40.073 \%$ & $35.077 \%$ & $21.527 \%$ \\
\hline & $\mathrm{TiO}_{2}$ & $0.831 \%$ & $0.338 \%$ & $0.860 \%$ & $0.556 \%$ & $0.653 \%$ & $0.838 \%$ & $4.037 \%$ \\
\hline & $\mathrm{MnO}$ & $0.173 \%$ & $0.015 \%$ & $0.044 \%$ & $0.006 \%$ & $0.563 \%$ & $0.043 \%$ & $0.428 \%$ \\
\hline & $\mathrm{Fe}_{2} \mathrm{O}_{3}$ & $7.368 \%$ & $1.081 \%$ & $3.726 \%$ & $0.202 \%$ & $0.101 \%$ & $0.494 \%$ & $2.655 \%$ \\
\hline & $\mathrm{CuO}$ & $0.007 \%$ & $0.002 \%$ & $0.007 \%$ & $0.035 \%$ & $0.002 \%$ & $0.049 \%$ & $0.066 \%$ \\
\hline & ZnO & $0.019 \%$ & $0.020 \%$ & $0.019 \%$ & $0.009 \%$ & $0.003 \%$ & $0.394 \%$ & $1.335 \%$ \\
\hline & $\mathrm{ZrO}_{2}$ & $0.038 \%$ & $0.018 \%$ & $0.027 \%$ & $0.033 \%$ & $0.034 \%$ & $0.011 \%$ & $0.042 \%$ \\
\hline & $\mathrm{BaO}$ & $0.094 \%$ & $0.174 \%$ & $0.100 \%$ & $0.174 \%$ & $0.153 \%$ & $0.142 \%$ & $0.213 \%$ \\
\hline & $\mathrm{Cl}$ & $0.040 \%$ & $0.040 \%$ & $0.040 \%$ & $0.040 \%$ & $0.040 \%$ & $0.040 \%$ & $0.040 \%$ \\
\hline & $\mathrm{Co}_{2} \mathrm{O}_{3}$ & $0.007 \%$ & $0.003 \%$ & $0.004 \%$ & $0.005 \%$ & $0.004 \%$ & $0.003 \%$ & $0.000 \%$ \\
\hline & SrO & $0.021 \%$ & $0.100 \%$ & $0.108 \%$ & $0.107 \%$ & $0.074 \%$ & $0.031 \%$ & $0.053 \%$ \\
\hline & $\mathrm{Y}_{2} \mathrm{O}_{3}$ & $0.007 \%$ & $0.005 \%$ & $0.007 \%$ & $0.004 \%$ & $0.009 \%$ & $0.007 \%$ & $0.016 \%$ \\
\hline \multicolumn{2}{|c|}{ (Ca/Si)Oxides } & 0.104 & 2.469 & 0.096 & 2.162 & 1.068 & 2.13 & 0.798 \\
\hline \multicolumn{2}{|c|}{$(\mathrm{Si}+\mathrm{Al}+\mathrm{Fe})$ oxides } & $70.19 \%$ & $28.84 \%$ & $54.09 \%$ & $31.85 \%$ & $42.92 \%$ & $17.09 \%$ & $31.96 \%$ \\
\hline \multicolumn{2}{|c|}{$\mathrm{pH}$} & 6.05 & 12.1 & 12.3 & 12.65 & 8.5 & 12.1 & 12.4 \\
\hline \multicolumn{2}{|c|}{$\begin{array}{c}\text { Specific surface area, } \\
\text { BET }\left(\mathrm{m}^{2} / \mathrm{Kg}\right)\end{array}$} & 452 & 431 & 493 & 460 & 505 & 455 & 849 \\
\hline \multicolumn{2}{|c|}{ Density $\left(\mathrm{g} / \mathrm{cm}^{3}\right)$} & 2.732 & 2.956 & 2.41 & 2.422 & 2.905 & 2.851 & 2.653 \\
\hline \multicolumn{2}{|c|}{$\begin{array}{c}\text { Mean partial size } \\
(\mu \mathrm{m})\end{array}$} & 15.71 & 19.49 & 14.02 & 15.17 & 12.28 & 13.18 & 137.1 \\
\hline \multicolumn{2}{|c|}{$\mathrm{D}_{10}(\mu \mathrm{m})$} & 1.029 & 1.556 & 0.952 & 1.2 & 0.689 & 0.941 & 1.594 \\
\hline \multicolumn{2}{|c|}{$\mathrm{D}_{90}(\mu \mathrm{m})$} & 36.80 & 43.08 & 34.26 & 38.27 & 30.58 & 30.53 & 356.2 \\
\hline
\end{tabular}

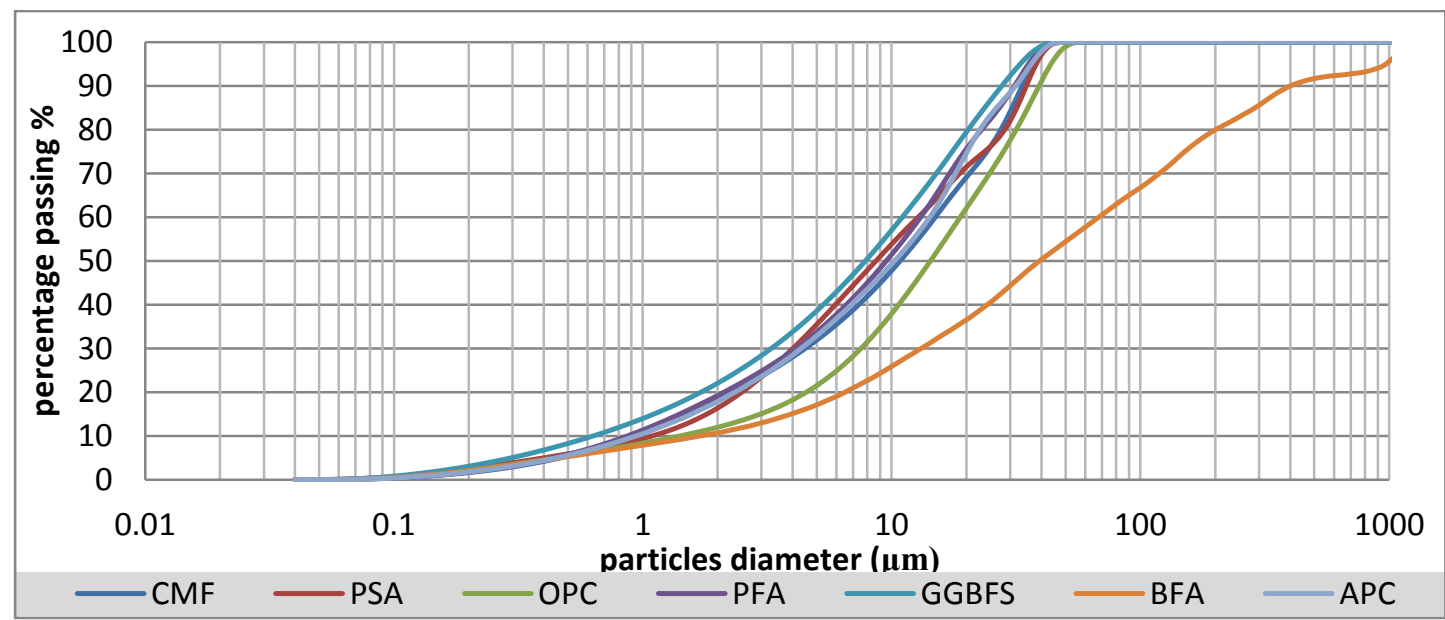

Figure (2). Particle size distributions for the selected fillers 

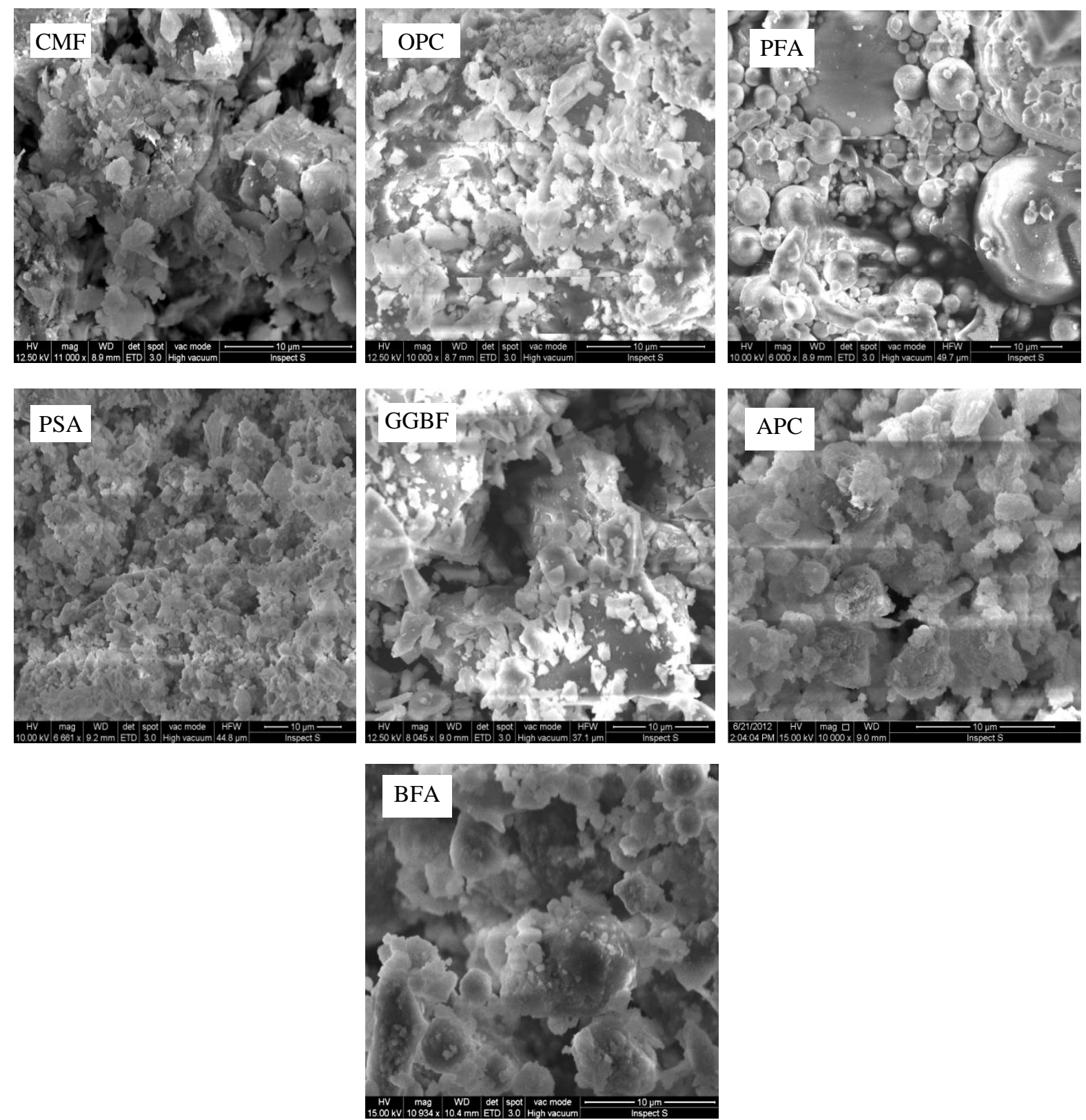

Figure (3). Morphology of the selected fillers

\subsection{Results Discussion}

Filler plays significant physical and chemical roles in controlling final CBEM properties. Its physical and chemical characteristics could influence all preparations and service life stages. Thus, in this study, fundamental test methods were used to characterize selected fillers' properties. This helped in identifying the candidate waste filler needed to replace the OPC in CBEM in a more professional method. In contrast to $\mathrm{OPC}$, the selected fillers were exposed to the following characteristics: 


\subsubsection{Alkaline nature}

Alkaline nature of the filler compositions could be helpful in increasing the alkalinity in the pores. Consequently, it activates the pozzolanic materials in the hydration process. Additionally, increasing the alkalinity will increase the coalescence of the bitumen emulsion, which ends in faster setting and strength gain. Lime is mainly the responsible of the alkaline, but sodium and potassium are associated with less percentage (Lampris et al., 2008). However, none of the waste fillers exceeded the lime content of OPC, but PSA was found to be very close, CMF is the lowest, as can be seen in Table (1). Also, APC and BFA exceed the OPC in terms of sodium and potassium content, respectively. Thus, with regard to high lime content, PSA impacts the alkalinity more than other fillers.

\subsubsection{Cementitious Action}

Introducing filler material having cementitious properties to CBEM possesses three advantages. Firstly, hydration products offer secondary binding material. Secondly, secondary binding material reinforces the bitumen binder; and thirdly, the hydration process increases coalescence of bitumen emulsion by absorbing the water. In fact, the absorption is continued after coalescence by absorbing trapped water between the bitumen and aggregate. The critical components of OPC are calcium silicates, but also other oxides are very significant to the cement phases, and consequently its properties (Domone and Illston, 2010). These other main oxides are the aluminium and iron oxides, and the lesser ones are magnesium, sodium and potassium. However, the selected waste fillers showed variation in content of these oxides. In contrast to OPC, PSA showed close values of $\mathrm{Ca} / \mathrm{Si}$ ratio and the sum of $\mathrm{Si}, \mathrm{Fe}$ and $\mathrm{Al}$, Table (1). It can be seen from Figure (2) that the PSA has almost identical oxide content to OPC, while PFA tends to be similar to CMF. Other waste fillers showed less similarity in their oxide content. Thus, it is expected that PSA will provide a better hydration process than other waste fillers, when used as a replacement to the filler in CBEM.

\subsubsection{Surface Area and Particle Size}

Particle size and finesse of filler materials have an energetic effect on properties of CBEM in two terms: physically and chemically. The finer particle materials lead to backing the pores by these particales and the production of a denser skeleton. Also, increasing the finesse increases the reactive surface and more hydration process is expected. Furthermore, increasing the surface area will increase the water absorption, and it may affect the workability of the mix after a certain value. Table (1) shows that all fillers have a surface area more than OPC, which is a positive indication that fillers' surfaces will show activity in the present of water, consequently more hydration process is expected. From the same table and from Figure (2), the particle size properties showed that all fillers except BFA are fine and well graded, which is another positive indication in terms of mix backing properties. Compared to OPC, BFA has coarser particle size characteristics, with very high specific surface area; this is due to the high 
porous properties of BFA particles. In any case, waste fillers have shown superior properties to OPC in terms of particle size and specific surface area.

\subsubsection{Morphology}

Morphology of the filler is significant in influencing the properties of the fresh CBEM in terms of the workability and total water absorption. Highly porous filler with agglomerated particles' morphology will absorb more water in its pores (Segui et al., 2012). Also, sharp angles and irregular shape particles interrupt the workability, while the spherical shapes do the inverse (Thanaya, 2003). From Figure (3) it is clear that OPC and GGBFS have sharp and irregular shape particles; PFA has almost spherical shape particles while PSA, APC and BFA have agglomerated irregular particles, especially PSA. Accordingly, the last mention fillers are obviously absorbing high water and they will significantly impact workability, in contrast to PFA. On the other hand, the sharp shape factor affects the workability for the OPC and GGBFS.

\section{Characteristics of CBEM Comprising Waste Fillers}

In order to explore the effect of introducing different type of waste filler on the properties of CBEM, different levels of each filler were incorporated as a replacement to CMF. The main aim was to explore the interaction of each filler with the rest of the CBEM contents to produce high value CBEM for roads and highway construction.

\subsection{Mix Design}

Details mix design procedure is explained elsewhere in early-published study works (Al-Busaltan, 2012, Al Nageim et al., 2012, Al-Busaltan et al., 2012a). However, emulsion type, emulsion content, aggregate type, aggregate gradation, pre-wetting water content, mixing procedure, compaction method, curing procedure and number of specimens were fixed for comparison purposes among different filler types. Five replacement percentages of CMF with new waste filler were used, while the Indirect Tensile Stiffness Modulus (ITSM) test was used to identify the effect of waste filler level on the strength of the developed CBEM. The stiffness was measured after 2, 7, 14, 28, 90, 180 and 360 days to ensure the development in strength at long-term periods.

\subsection{Results and discussion}

The tables and figures below present the test results of CBEM comprising the said selected waste filler, which include strength in terms of stiffness modulus and volumetric characteristics in terms of density and porosity. Also, for comparison purposes, the ratio of stiffness of CBEM of specific filler type and percentage at 2 days to the stiffness of CBEM comprised OPC at the same percentage are tabulated. The stiffness of hard and soft Hot Mix Asphalt (HMA) are also presented in the figures. However, the test results and discussion due to replacing of CMF with waste fillers are as follows: 


\subsubsection{PFA}

Results of replacing CMF by PFA presented in Table (2) and Figure (4) raised the following:

* The increase in the percentage of replacement leads to a slight improvement in ITSM

* The increase in the percentage of replacement results in increases in stiffness value with time, but after 3 months no significant improvement has been noticed

* Increasing the percentage of replacement decreases the stiffness ratio to OPC

* The stiffness values of CBEM comprising PFA are very inferior to HMA

There are slight decreases in density of CBEM and increases in porosity with the increase of percentage of replacement

Table (2). ITSM performance for CBEMs comprising PFA

\begin{tabular}{|l|c|c|c|c|}
\hline Mixture Type & $\begin{array}{c}\text { ITSM@ 2day } \\
(\mathrm{MPa})\end{array}$ & $\begin{array}{c}\text { Stiffness ratio to } \\
\text { OPC }\end{array}$ & $\begin{array}{c}\text { Bulk Density } \\
\left(\mathrm{g} / \mathrm{cm}^{3}\right)\end{array}$ & Air Void, $(\%)$ \\
\hline CM & 182 & 100 & 2.151 & 11.24 \\
\hline CM-PFA $^{1.375}$ & 230 & 92 & 2.150 & 11.13 \\
\hline CM-PFA $^{2.75}$ & 245 & 41 & 2.140 & 11.45 \\
\hline CM-PFA $^{4.125}$ & 285 & 31.7 & 2.126 & 11.90 \\
\hline CM-PFA & 5.5 & 27.3 & 2.376 & 12.09 \\
\hline HMA143 & 300 & 1482 & 2.357 & 4.91 \\
\hline HMA53 & & 3714 & & \\
\hline
\end{tabular}

The slight improvement in stiffness with increasing PFA content is mainly due to alkaline properties and higher surface area. This also explained the improvement in the early age, where there is no noticeable strength improvement with the increase in PFA percentage, whereas the strength after early age is mainly dependent on the breaking of the emulsion. On the other hand, the increase in porosity is a result of increasing the free water due to the increases in coalescence of emulsion with increases in PFA content. Free water is forcing the compaction effort, consequently reducing the density of the mix. Nevertheless, both volumetric and strength properties results are fruitless, as after one year they reached only $70 \%$ of soft HMA stiffness values 


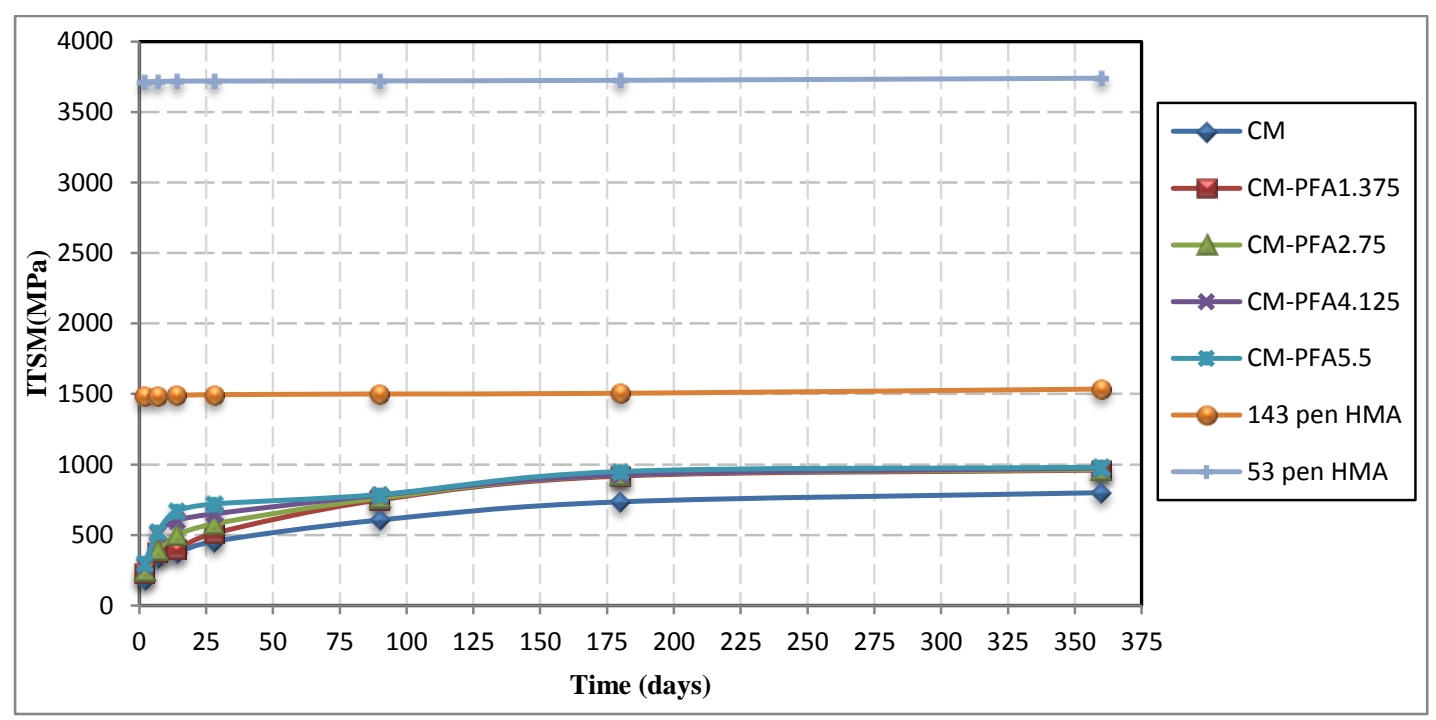

Figure (4). Effect of PFA percentage on ITSM

\subsubsection{PSA}

Table (3) and Figure (5) present the volumetric and stiffness results of CBEMs comprising range of PSA level as a replacement of CMF. The main points to note are:

Increasing the percentage of PSA replacement leads to

- significant improvement in ITSM

- steadily increases in stiffness value within early age, but the rate of increment decreases after that

- Increase in the stiffness ratio to OPC.

* The stiffness values of CBEM comprising high percentages of PSA are comparative to that of soft HMA at early age. While ITSM values become comparative to hard HMA after just 2-3 weeks.

* There is insignificant variation in density and porosity with the variation in PSA replacement levels.

Replacing CMF by PSA introduces significant improvement in the stiffness modulus, which is due to: high alkaline properties of PSA, cementitious properties - which is identical to OPC, high surface area and agglomerated and porous mineral morphology. Thus, with increasing PSA percentages:

- Coalescence of bitumen emulsion increased due to rise in $\mathrm{pH}$, where the $\mathrm{pH}$ in the mixture's pores changes from around 6 to about 12.65 .

* Hydration products improved due to added in hydraulic portion supplied by PSA. These products lead to initiate secondary binding material, and simultaneously strengthen and reinforce the primary bitumen binder. 
Absorption of water improved as a result of the hydration process, and also the high absorbability of PSA resulted from its morphology, high surface area and chemical phases.

PSA showed better strength than OPC mainly due to the last mentioned point, i.e. the high PSA absorption which facilitates the gain in strength, as it removes the trapped water (the main cause of inferior CBEM strength). Also, absorption of water reduces the workability and results in a slight reduction in density and slight increase in porosity.

Table (3). ITSM performance for CBEMs comprising PSA

\begin{tabular}{|l|c|c|c|c|}
\hline Mixture Type & $\begin{array}{c}\text { ITSM@ 2day } \\
(\mathrm{MPa})\end{array}$ & $\begin{array}{c}\text { Stiffness ratio to } \\
\text { OPC }\end{array}$ & $\begin{array}{c}\text { Bulk Density } \\
\left(\mathrm{g} / \mathrm{cm}^{3}\right)\end{array}$ & Air Void, $(\%)$ \\
\hline CM & 182 & 100 & 2.151 & 11.24 \\
\hline CM-PSA $^{1.375}$ & 256 & 102.4 & 2.139 & 11.64 \\
\hline CM-PSA $^{2.75}$ & 627 & 104.5 & 2.137 & 11.58 \\
\hline CM-PSA $^{4.125}$ & 1068 & 118 & 2.138 & 11.43 \\
\hline CM-PSA $^{5.5}$ & 1782 & 162 & 2.145 & 11.13 \\
\hline HMA143 & & 1482 & 2.376 & 3.91 \\
\hline HMA53 & \multicolumn{2}{|r|}{3714} & 2.357 & 4.67 \\
\hline
\end{tabular}

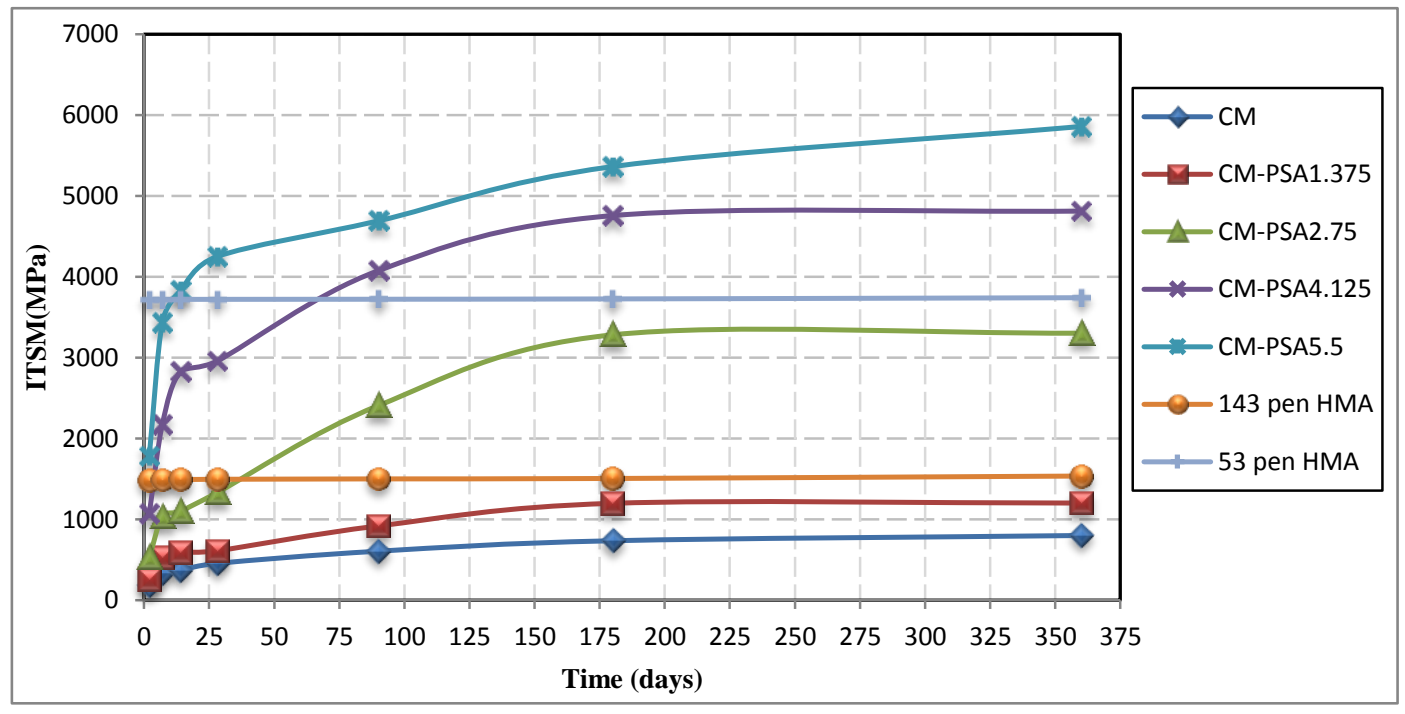

Figure (5). Effect of PSA percentage on ITSM

\subsubsection{GGBFS}

Results of CBEMs comprising various percentages of replacement of CMF by GGBFS are presented in Table (4) and Figure (6), in which the following can be reported:

* Increasing the percentage of replacement results in 
- a small improvement in ITSM

- increase in stiffness value with time with a steadily increase at early ages

- decrease in stiffness ratio compared with that of OPC

- slight decreases in density and increases in porosity with increase in percentage of replacement.

The stiffness values of CBEMs comprising GGBFS are poorer than that of HMA.

Improvement in CBEM comprising GGBFS is mainly from the lime content, which is contributed in produceing hydration products. Unfortunately, these products are not sufficient to initiate sufficient secondary binder as is the case with both PSA and OPC. Although the high surface area will help in absorbing water and improving strength, the $\mathrm{pH}$ level is not enough to permit high hydration and coalescence. The surface area and hydration process also contribute to the slight reduction in density and the small increases in porosity. GGBFS needs activator to explore its potential hydration properties, where alone it cannot offer any significant improvement in CBEM compared with HMA or CBEM comprising OPC.

Table (4). ITSM performance for CBEMs comprising GGBFS

\begin{tabular}{|l|c|c|c|c|}
\hline Mixture Type & $\begin{array}{c}\text { ITSM@ 2day } \\
(\mathrm{MPa})\end{array}$ & $\begin{array}{c}\text { Stiffness ratio to } \\
\text { OPC }\end{array}$ & $\begin{array}{c}\text { Bulk Density } \\
\left(\mathrm{g} / \mathrm{cm}^{3}\right)\end{array}$ & Air Void, $(\%)$ \\
\hline CM & 182 & 100 & 2.151 & 11.24 \\
\hline CM-GGBFS $^{1.375}$ & 185 & 74 & 2.136 & 11.94 \\
\hline CM-GGBFS $^{2.75}$ & 290 & 48.3 & 2.139 & 11.86 \\
\hline CM-GGBFS $^{4.125}$ & 380 & 42 & 2.142 & 11.78 \\
\hline CM-GGBFS & 462 & 42 & 2.376 & 3.91 \\
\hline HMA143 & 462 & 1482 & 2.357 & 4.67 \\
\hline HMA53 & & 3714 & & 2.19 \\
\hline
\end{tabular}

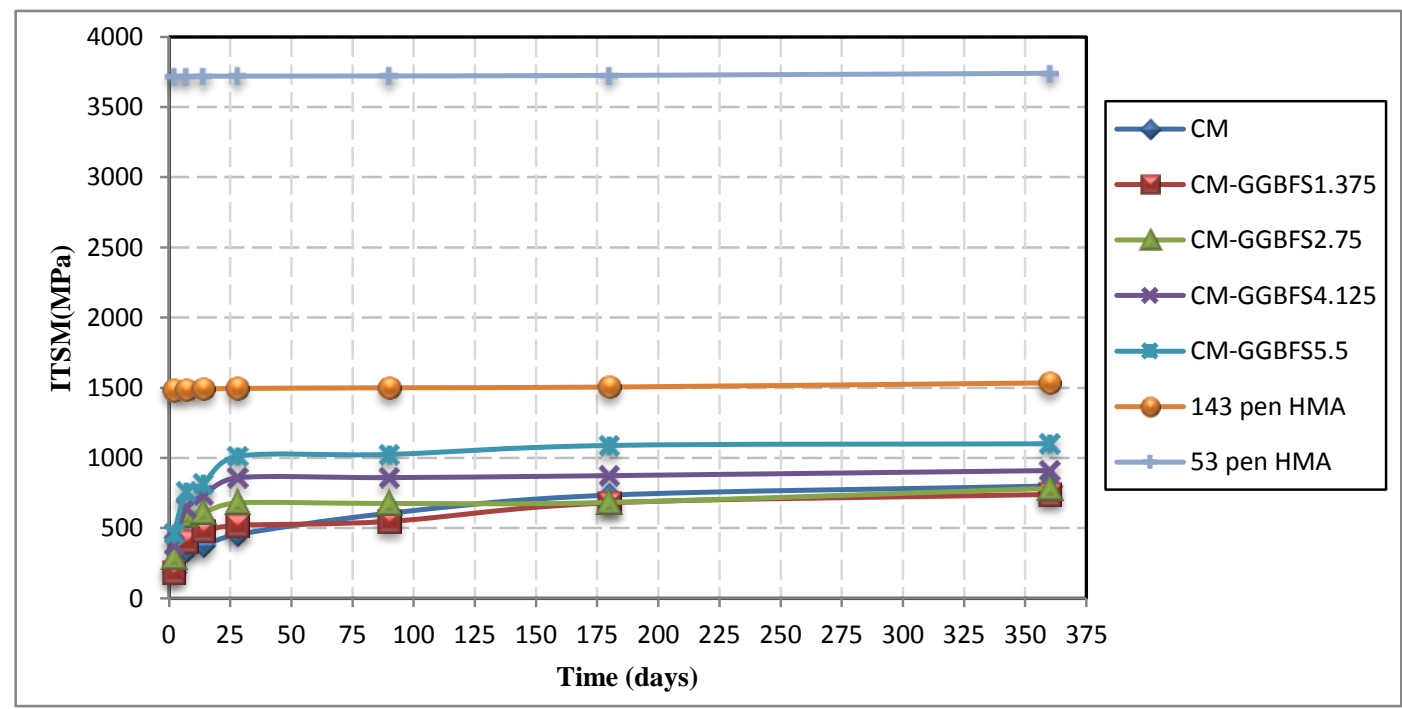

Figure (6). Effect of GGBFS percentage on ITSM 


\subsubsection{APC}

Results of CBEMs comprising various percentages of replacement of CMF by APC are presented in Table (5) and Figure (7), which indicate almost identical behaviour to CBEMs containing GGBFS with slight reduction in stiffness values and porosity. The high alkaline of APC is the main possible cause of the gain in stiffness in the early age. The relatively high lime content is unbeneficial without the other oxides, namely $\mathrm{Si}, \mathrm{Al}$ and $\mathrm{Fe}$, to generate hydration products; while the agglomerated morphology helps in absorbing free water, consequently reducing the porosity.

Table (5). ITSM performance for CBEMs comprising APC

\begin{tabular}{|c|c|c|c|c|}
\hline Mixture Type & $\begin{array}{l}\text { ITSM@2day } \\
\text { (MPa) }\end{array}$ & $\begin{array}{c}\text { Stiffness ratio to } \\
\text { OPC }\end{array}$ & $\begin{array}{l}\text { Bulk Density } \\
\qquad\left(\mathrm{g} / \mathrm{cm}^{3}\right)\end{array}$ & Air Void, (\%) \\
\hline $\mathrm{CM}$ & 182 & 100 & 2.151 & 11.24 \\
\hline CM-APC ${ }^{1.375}$ & 138 & 55.2 & 2.162 & 10.83 \\
\hline CM-APC ${ }^{2.75}$ & 217 & 36.2 & 2.175 & 10.35 \\
\hline CM-APC ${ }^{4.125}$ & 285 & 31.5 & 2.179 & 10.13 \\
\hline CM-APC ${ }^{5.5}$ & 346 & 31.4 & 2.192 & 9.76 \\
\hline HMA143 & \multicolumn{2}{|c|}{1482} & 2.376 & 3.91 \\
\hline HMA53 & \multicolumn{2}{|c|}{3714} & 2.357 & 4.67 \\
\hline
\end{tabular}

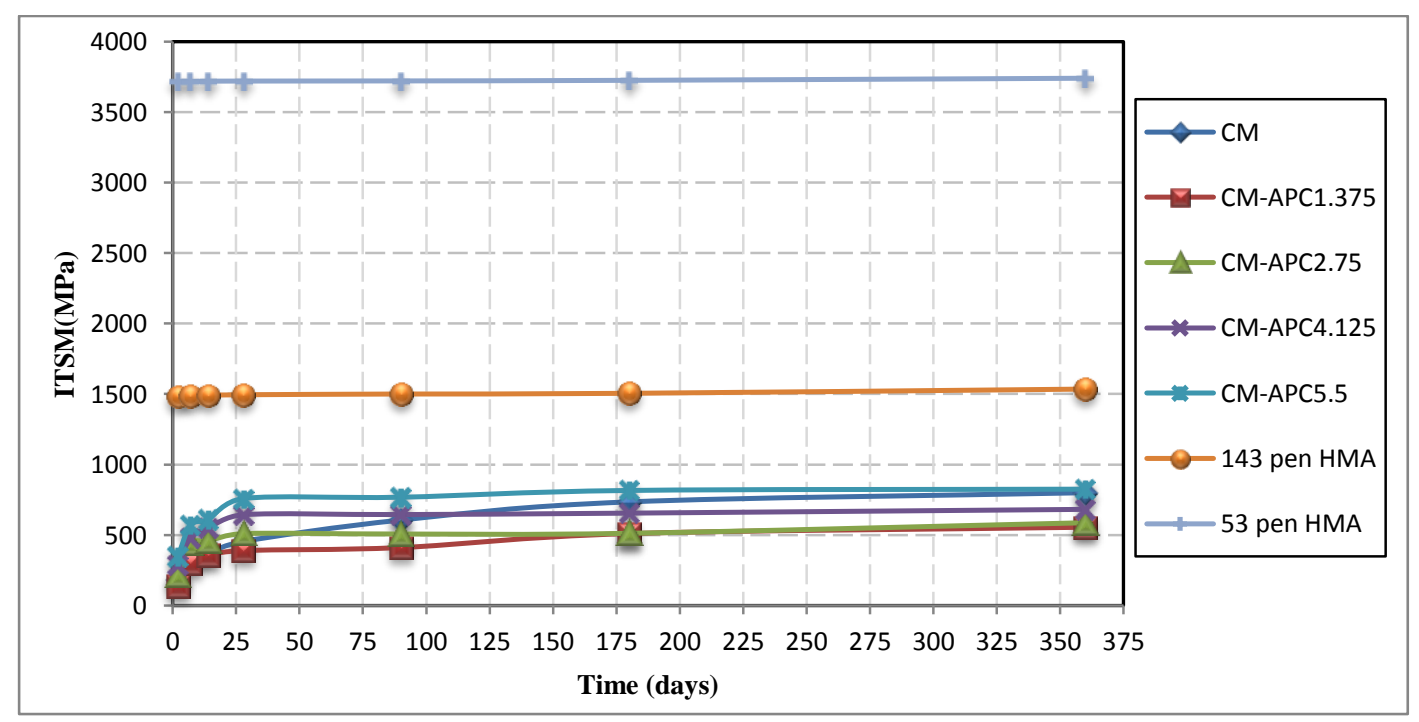

Figure (7). Effect of APC percentage on ITSM

\subsubsection{BFA}

Table (6) and Figure (8) present the results of CBEM comprising BFA as a replacement to CMF. The results have demonstrated the following: 
Unnoticeable improvement in stiffness at early age, but after one week stiffness increases with adding more BFA.

* Increasing the percentage of replacement causes reduction in stiffness ratio compared with CBEM containing OPC.

* The stiffness values of CBEMs comprising BFA are relatively poorer compared with HMA.

* There is a slight decrease in density and increase in the mix porosity with the increase in the percentage of replacement.

Table (6). ITSM performance for CBEMs comprising BFA

\begin{tabular}{|l|c|c|c|c|}
\hline Mixture Type & $\begin{array}{c}\text { ITSM@ 2day } \\
(\mathrm{MPa})\end{array}$ & $\begin{array}{c}\text { Stiffness ratio to } \\
\text { OPC }\end{array}$ & $\begin{array}{c}\text { Bulk Density } \\
\left(\mathrm{g} / \mathrm{cm}^{3}\right)\end{array}$ & Air Void, (\%) \\
\hline CM & 182 & 100 & 2.151 & 11.24 \\
\hline CM-BFA $^{1.375}$ & 180 & 72 & 2.163 & 10.74 \\
\hline CM-BFA $^{2.75}$ & 195 & 32.5 & 2.145 & 11.46 \\
\hline CM-BFA $^{4.125}$ & 199 & 22 & 2.130 & 12.01 \\
\hline CM-BFA & & 17.7 & 2.376 & 11.88 \\
\hline HMA143 & 195 & 1482 & 2.357 & 3.91 \\
\hline HMA53 & & 3714 & & 4.67 \\
\hline
\end{tabular}

The high alkaline and surface area, further to agglomerated morphology of BFA, results in an increase in the rate of coalescence of bitumen emulsion, which means an increase in the trapped water. Unfortunately, BFA offered insufficient cementitious portion, as can be seen in Table (1), thus the trapped water prevents the gain in strength at first week. Therefore, the water removal will depend on evaporation only. This explains the steadily improvement that happens when most of the trapped water evaporates during early weeks. The relatively high trapped water at early ages also causes slight reduction in density and increases porosity; as the trapped water dissipates the compaction effort. 


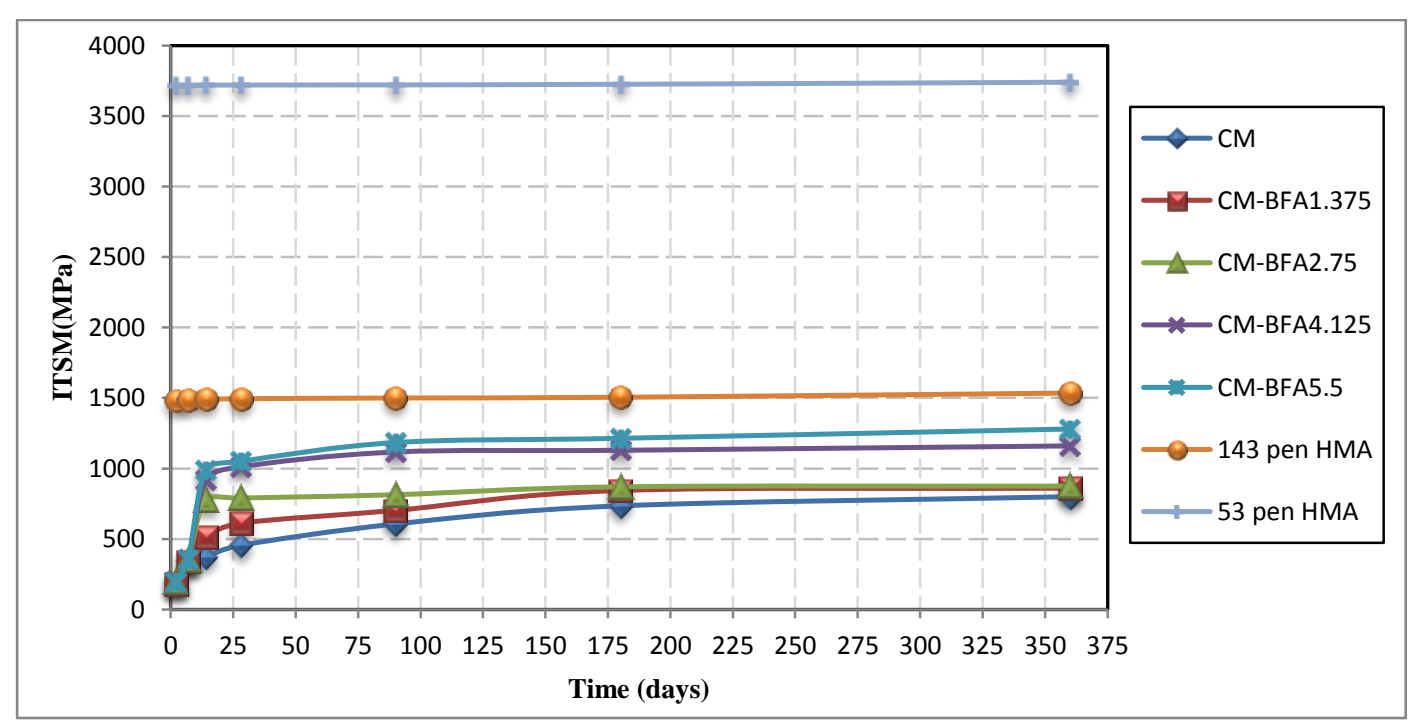

Figure (8). Effect of BFA percentage on ITSM

\section{Conclusions}

The tests described above allow the following conclusions to be drawn regarding the ability of various waste or by-product materials to improve the characteristics of CBEM:

1. Characterising the filler offers a valid tool to predict its validity in improving CBEM properties. This characterisation may include chemical compositions, $\mathrm{pH}$ value, surface area and particles' morphology.

2. The successful candidate among the studied fillers used to improve CBEM properties should possess a combination of high $\mathrm{pH}$, surface area, and cementitious chemical phases further to agglomerating morphology.

3. Generally, stiffness increases with the increase in selected fillers' (PFA, PSA, GGBFS, APC and BFA) replacement level.

4. Generally, the porosity increases slightly with the increase in the selected fillers' (PFA, PSA, GGBFS, APC and BFA) level.

5. Among the selected fillers (PFA, PSA, GGBFS, APC and BFA) PSA only showed significant improvement in the ITSM of CBEMs compared with both HMA and CBEM containing OPC.

\section{Acknowledgements}

The author wish to thank School of Built Environment, Liverpool John Moores University, Liverpool, United Kingdom and especially Professor Hassan Al Nageim for their help and supports in this research work. 


\section{References}

AL-BUSALTAN, S., AL NAGEIM, H., ATHERTON, W. \& SHARPLES, G. 2012a. Green Bituminous Asphalt relevant for highway and airfield pavement. Construction and Building Materials, 31, 243-250.

AL-BUSALTAN, S., AL NAGEIM, H., ATHERTON, W. \& SHARPLES, G. 2012b. Mechanical Properties of an Upgrading Cold-Mix Asphalt Using Waste Materials. Journal of Materials in Civil Engineering, 24, 1484-1491.

AL-BUSALTAN, S. F. S. 2012. DEVELOPMENT OF NEW COLD BITUMINOUS MIXTURES FOR ROAD AND HIGHWAY PAVEMENTS. PhD thesis, Liverrpool John Moores University.

AL NAGEIM, H., AL-BUSALTAN, S. F., ATHERTON, W. \& SHARPLES, G. 2012. A comparative study for improving the mechanical properties of cold bituminous emulsion mixtures with cement and waste materials. Construction and Building Materials, 36, 743-748.

BROWN, S. F. \& NEEDHAM, D. 2000. A Studay of Cement Modified Bitumen Emulsion Mixtures. AAPT. Reno, Nevada

BSI 2002. BS EN 13043:2002 Aggregates for bituminous mixtures and surface treatments for roads, airfields and other trafficked areas. British Standard Institution, London, UK.

BSI 2008. BS EN 1097-7:2008 Tests for mechanical and physical properties of aggregates - Part 7: Determination of the particle density of filler - Pyknometer method. London, UK.

CONCRETE SOCIETY 1991. The use of GGBS and PFA in Concrete. ConcreteSociety report No.40. Slough, UK.

DOMONE, P. \& ILLSTON, J. 2010. Construction Materials their Nature and Behaviour, Spon Press.

ENVIRONMENTAL EGENCY 2008. Pulverised fuel ash and furnace bottom ash, a technical report on the manufacture of products from pulverised fuel ash (PFA) and furnace bottom ash (FBA). Banbury, Oxon, UK: Enviromental Agency.

GEYSEN, D., VANDECASTEELE, C., JASPERS, M. \& WAUTERS, G. 2004. Comparison of immobilisation of air pollution control residues with cement and with silica. Journal of Hazardous Materials, 107, 131-143.

HEAD, R. W. 1974. An informal report of cold mix research using emulsified asphalt as a binder. Association of Asphalt Paving Technologists Proceeding (AAPT).

JERATH, S. \& HANSON, N. 2007. Effect of fly ash content and aggregate gradation on the durability of concrete pavements. Journal of Materials in Civil Engineering, 19, 367-375. 
KARAMI, S. 2008. Using By-product Industrial Materials to Replace All Cement in Construction Products. PhD theis Coventry University, UK.

LAMPRIS, C., STEGEMANN, J. A. \& CHEESEMAN, C. R. 2008. Chloride leaching from air pollution control residues solidified using ground granulated blast furnace slag. Chemosphere, 73, 1544-1549.

LI, G., ZHAO, Y., PANG, S. S. \& HUANG, W. 1998. Experimental Study of Cement-Asphalt Emulsion Composite. Cement and Concrete Research, 28, 635-641.

NAIK, T. R., RAMME, B. W. \& TEWS, J. H. 1994. USE OF HIGH VOLUMES OF CLASS-C AND CLASS-F FLY-ASH IN CONCRETE. Cement Concrete and Aggregates, 16, 12-20.

NIAZI, Y. \& JALILI, M. 2009. Effect of Portland cement and lime additives on properties of cold in-place recycled mixtures with asphalt emulsion. Construction and Building Materials, 23, 1338-1343.

ONER, A. \& AKYUZ, S. 2007. An experimental study on optimum usage of GGBS for the compressive strength of concrete. Cement and Concrete Composites, 29, 505514.

ORUC, S., CELIK, F. \& AKPINAR, V. 2007. Effect of Cement on Emulsified Asphalt Mixtures. Journal of Materials Engineering and Performance, Vol.16 (5), PP.578-583.

SAINTON, A. \& BOURDREL, D. 1993. Cold Double Treatment Process of Road Materials with Portland Cement and Asphalt Emulsion. 5th Eurobitume Congress Stockholm, Sweden.

SARıDEMIR, M., TOPÇU, İ. B., ÖZCAN, F. \& SEVERCAN, M. H. 2009.Prediction of long-term effects of GGBFS on compressive strength of concrete by artificial neural networks and fuzzy logic. Construction and Building Materials, 23, 1279-1286.

SCHMIDT, R. J., SANTUCCI, L. E. \& COYNE, L. D. 1973. PERFORMANCE CHARACTERISTICS OF CEMENT-MODIFIED ASPAHLT EMULSION MIXES. Association of Asphalt Paving Technologists Proceeding (AAPT).

SEGUI, P., AUBERT, J. E., HUSSON, B. \& MEASSON, M. 2012. Characterization of wastepaper sludge ash for its valorization as a component of hydraulic binders. Applied Clay Science, 57, 79-85.

SHIRAZI, H. \& NRC 1999. Field and laboratory evaluation of the use of lime fly ash to replace soil cement as a base course. Seventh International Conference on LowVolume Roads 1999, Vol 1: Planning, Administration, and Environment; Design; Materials, Construction, and Maintenance; Operations and Safety.

SONG, H.-W. \& SARASWATHY, V. 2006. Studies on the corrosion resistance of reinforced steel in concrete with ground granulated blast-furnace slag - An overview. Journal of Hazardous Materials, 138, 226-233.

TAYLOR, H. F. W. 1997. Cement chemistry, Thomas Telford. 
TERRELL, R. L. \& WANG, C. K. 1971. EARLY CURING BEHAVIOR OF CEMENT MODIFIED ASPHALT EMULSION MIXTURES. Association of Asphalt Paving Technologists Proceeding (AAPT).

UEMURA, T. \& NAKAMORI, Y. 1993. Stabilization process of cement-asphalt emulsion in Japan. First World Congress on Emulsion. Paris. 